\title{
Novel Co/UiO-66 metal organic framework catalyst for oxygen reduction reaction in microbial fuel cells
}

\author{
Zhenxin $\mathrm{Chen}^{1}$, Qikai $\mathrm{Wu}^{1}$, and Hongguo Zhang ${ }^{1,2, *}$ \\ ${ }^{1}$ GuangZhou University, School Environmental Sciences and Engineering, Key Laboratory for Quality and Conservation of Pearl River \\ Delta, Guangdong Provincial Key Laboratory of Radionuclides Pollution Control and Resources, 510006 Guangzhou, PR China \\ ${ }^{2}$ GuangZhou University, Guangzhou University-Linkoping University Research Center on Urban Sustainable Development, 510006 \\ Guangzhou, PR China
}

\begin{abstract}
To improve the power generation of microbial fuel cell (MFC), the cathode is modified to increase its oxygen reduction reaction (ORR) activity by using $\mathrm{Co} / \mathrm{UiO}-66$, which derived from pyrolyzing the mixture of $\mathrm{Co}(\mathrm{NO} 3)_{2}$ as the metal precursor incorporated with $\mathrm{NH}_{2}-\mathrm{UiO}-66$. It was found that $\mathrm{Co} / \mathrm{UiO}-66(\mathrm{MOF}-900)$ has been developed as a high-performance electrocatalyst for ORR at a pyrolysis temperature of $900{ }^{\circ} \mathrm{C}$. Therefore, Co/UiO-66 should be a promising oxygen reduction catalyst for application in MFCs. This study provides technical and theoretical validation for the MFC performance improvement by ORR active MOFderived catalysts modified cathodes.
\end{abstract}

\section{Introduction}

Energy shortage and environmental pollution are the most pressing issues that have to be addressed in order to realize the sustainable development of human society. As a new type of energy conversion device, Microbial fuel cells(MFCs) hold great potential to meet both challenges because they could decompose organic waste through biological oxi-dation and produce electrical energy simultaneously[1-3]. At the anode chamber of MFCs, electrons and protons are produced from the oxidation of organic compounds by microbes, and then transferred to cathode through an external circuit. These electrons are consumed by electron acceptors in cathode. Finally, bioelectricity is generated by the electrochemical process $[4,5]$. Among various kinds of MFCs, air-cathode MFC is most widely applied for its simple configuration and direct use of accessible oxygen as electron acceptors [6,7].

Of all bio-electrochemical process, the cathodic oxygen reduction reaction (ORR) is a key factor for the overall performance and the power output density of MFCs. However, oxygen reduction reaction (ORR) in cathode is quite sluggish, so highly efficient catalysts are essential to speed up the rate and reduce the cathode overpotential [8,9]. Platinum (Pt)-based catalysts, possessing excellent ORR catalytic activity, have boosted various novel techniques such as hydrogen production, super capacitor, and have been commonly used in MFCs. But the high cost, scarcity, and sensitivity to poisoning greatly hinder their practical application [10-12]. Therefore, it is urgent to develop efficient and low-cost ORR catalysts to replace Pt.

Up to now, numerous studies have been devoted to fabricate highly active electrocatalysts for ORR. Noble metal oxides [13-15], carbon-based materials [16-18], transition metal heteroatom doped carbons [19-21] and nitrogen-doped carbonaceous materials [22], have been developed as promising alternatives to replace Pt-based catalysts. In particular, the transition metal heteroatom doped carbons stand out from all other promising candidates owing to their superb ORR electrocatalytic properties. In addition, the intimate contact between the transition metal and carbon shell is critical to influence the structure of composites with the metal active sites, which can significantly affect the electron transmission capability between carbon matrix and metal atoms and the kinetics rate of the ORR. Although the transitionmetal heteroatom doped carbons have shown outstanding ORR activity, there still exists several technical hurdles of applying these catalysts are existing because of their low surface area, poor porosity structure, corrosion and severe aggregation, all of which deteriorate conductivity and ORR performance of catalysts [23,24]. Nowadays, abiotic non-Pt catalytic materials and biocatalysts are the main approaches to develop MFC cathode catalysts. Carbon material with high durability and the advantages of low price, are considered to be the most promising alternatives, and have been widely studied [25].

In recent years, a new kind of carbon material of metalorganic frameworks (MOFs) has attracted wide attention. MOFs are functional porous materials consisted of metal ion centers coordinated with organic ligands. MOFs have many unique properties, such as unsaturated metal ions in the active site, large specific surface area and pore structure, adjustable make them recently shows potential application in electrocatalysis [26]. It is found that during high-temperature activation, the organic part of MOFs will be converted to conductive carbon which is beneficial for

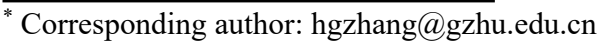


the electrical conductivity [27]. Hereby, MOFs have been served as pyrolytic precursor to prepare non-noble metal or/and heteroatom doped carbon-based materials with ORR catalytic activity [28]. After pyrolysis, the characteristics associated with electrocatalysis of MOFs, such as intrinsic ligand heteroatoms and metal centers, specific surface area and pore structures, will be retained to some extent or even be enhanced [29]. Chen et al. found that the efficient MOF-derived coralline-like catalyst favored fourelectron ORR process and achieved low overpotential for ORR comparable to benchmark $\mathrm{Pt} / \mathrm{C}$ [30]. Tang et al. reported that Co-MOF-derived dual metal and nitrogen heteroatom doped carbons displayed exceptional ORR property and high stability with onset potential of $0.347 \mathrm{~V}$ in pH-neutral electrolyte [31]. Meanwhile, You et al. found that MOF-derived porous nitrogen doped electrocatalyst favored the efficient four-electron pathway for ORR in MFC and the MFC achieved the maximum power density of $1665 \mathrm{~mW} / \mathrm{m}^{2}$, which was $39.8 \%$ higher than that for $\mathrm{Pt} / \mathrm{C}$ catalysts [32]. Fu et al. found that novel PeN-carbons could be synthesized using MOF UiO66- $\mathrm{NH}_{2}$ as precursor through calcination. The product has showed excellent catalytic activity for ORR which can be comparable to $\mathrm{Pt} / \mathrm{C}$ catalysts [33]. The customized functionalization and thermal conversion of MOFs can adjust the electronic structure of carbon layers and harvest more active sites for oxygen catalysis, providing an efficient synthetic route for the exploration of superior ORR electrocatalysts. The MOF-derived carbonaceous composites can inherit unique features of corresponding MOFs to fabricate non-noble metal heteroatom doped carbonaceous electrocatalyst with remarkable ORR performance, conductivity and stability. MOF-derived composites can not only possess the hosteguest synergistic effects between carbon and metal ion center, but also contain uniform alignment of metal ion centers in carbon matrix. The latter is favorable to build up adjustable 3D ordered network structure to mitigate the mass transfer barrier and aggregation of carbon. Therefore, it can be expected to enhance the electrical conductivity of ORR catalytic active MOFs and maintain/improve its catalytic activity through pyrolysis.

Consequently, in this study, $\mathrm{NH}_{2}-\mathrm{UiO}-66$ was synthesized by hydrothermal method, and $\mathrm{Co} / \mathrm{UiO}-66$ were prepared via pyrolyzing the mixture of $\mathrm{NH}_{2}-\mathrm{UiO}-66$ and $\mathrm{Co}\left(\mathrm{NO}_{3}\right)_{2}$ at different high temperature under the protection of nitrogen. Then cyclic voltammetry (CV) and linear sweep voltammetry (LSV) were adopted to evaluate the electrocatalytic activities of the as-prepared catalysts.

\section{Experiment}

\subsection{Synthesis of Catalysts}

$0.181 \mathrm{~g}$ 2-aminoterephthalic acid and $0.233 \mathrm{~g} \mathrm{ZrCl}_{4}$ were dispensed in $50 \mathrm{~mL} \mathrm{~N}$, N-dimethylformamide (DMF). Then, the mixed solution was transferred into a $100 \mathrm{~mL}$ Teflon lined steel autoclave and hydrothermally reaction at $120{ }^{\circ} \mathrm{C}$ for $48 \mathrm{~h}$. The solid $\mathrm{NH}_{2}-\mathrm{UiO}-66$ products were filtered and rinsed with $\mathrm{DMF}$ and methanol for several times, and then dried under the vacuum for $24 \mathrm{~h}$ at $80^{\circ} \mathrm{C}$.
The $\mathrm{Co}\left(\mathrm{NO}_{3}\right)_{2}$ as the metal precursor was incorporated with $\mathrm{NH}_{2}-\mathrm{UiO}-66$ to prepare $\mathrm{Co} / \mathrm{UiO} 66$ composites by impregnation method and calcination. 0.6 $\mathrm{mM} \mathrm{Co}\left(\mathrm{NO}_{3}\right)_{2}$ and $2 \mathrm{~g} \mathrm{NH}_{2}-\mathrm{UiO}-66$ were mixed in $15 \mathrm{~mL}$ methanol and the solution was stirred for $24 \mathrm{~h}$ at $40{ }^{\circ} \mathrm{C}$ by a magnetic stir bar to ensure complete loading of cobalt metal in $\mathrm{NH}_{2}-$ UiO-66. Subsequently, the mixture was centrifuged and washed with methanol, followed by drying at $80{ }^{\circ} \mathrm{C}$ under vacuum. Finally, the $\mathrm{Co} / \mathrm{UiO} 66$ products was pyrolyzed under protection of $\mathrm{N} 2$ between $700{ }^{\circ} \mathrm{C} 、 800^{\circ} \mathrm{C}$ and $900{ }^{\circ} \mathrm{C}$ for $2 \mathrm{~h}$ in programmable furnace with a rate of $5^{\circ} \mathrm{C}$ min-1. For simplicity, these samples were termed as MOF$\mathrm{T}$ (i.e., MOF-700、MOF-800、MOF-900), where T represented the pyrolysis temperature.

\subsection{Electrochemical Measurement}

The electrochemical measurements were conducted on electrochemical workstation (PalmSens4C, PalmSens BV, Netherlands) in a conventional three-electrode cell mode with $\mathrm{Ag} / \mathrm{AgCl}$ as the reference electrode, platinum wire plate as the counter electrode and glassy carbon electrode ( $5 \mathrm{~mm}$ diameter) as the working electrode. To prepare the working electrode, $3 \mathrm{mg}$ of $\mathrm{Co} / \mathrm{UiO} 66$ electrocatalysts were dispersed in $0.5 \mathrm{~mL}$ isopropanol and $0.5 \mathrm{~mL}$ deionized water contacting $20 \mu \mathrm{l}$ Nafion (5\%) solution in an ultrasonic bath for 10 min to produce the catalyst ink. $7.6 \mu \mathrm{l}$ suspension was dropped onto glass carbon electrode and dried at room temperature to form a uniform film. The cyclic voltammetry (CV) measurements was tested by electrochemical workstation in both nitrogen and oxygen saturated $0.1 \mathrm{M} \mathrm{KOH}$ electrolyte from -0.8 to $0.2 \mathrm{~V}$ at a scan rate of $50 \mathrm{mVs}^{-1}$. Rotating disk electrode (RDE) tests were carried out at the various rotation speeds from 250 to $2500 \mathrm{rpm}$ with a scanning rate of $10 \mathrm{mVs}^{-1}$ in $\mathrm{O}_{2}$-saturated alkaline and neutral electrolytes.

To further investigate the ORR performance of electrocatalysts, the rotating ring disk electrode (RRDE) measurements were carried out rotation speed controller (Pine, AFMSRCE 421701, USA) with $1600 \mathrm{rpm}$ rotating speed in $\mathrm{O}_{2}$-saturated $0.1 \mathrm{M} \mathrm{KOH}$ solution. The electron transfer number (n) and the hydrogen peroxide yield $\left(\mathrm{H}_{2} \mathrm{O}_{2} \%\right)$ can be calculated by the equations based on disk current $\left(\mathrm{I}_{\text {disk }}\right)$ and ring current $\left(\mathrm{I}_{\text {ring }}\right)$ of RRDE test.

$$
\begin{aligned}
n & =\left(4 I_{\text {disk }}\right) /\left(\text { Idisk }+I_{\text {ring }} / N\right) \\
H_{2} \mathrm{O}_{2} & =\left(200 * I_{\text {ring }} / N\right) /\left(\text { Idisk }+I_{\text {ring }} / N\right)
\end{aligned}
$$

Where $\mathrm{I}_{\text {ring }}, \mathrm{I}_{\text {disk }}$ and $\mathrm{N}$ are the ring current, disk current and collection efficiency $(\mathrm{N}=0.37)$, respectively for the employed RRDE.

\section{Result and Discussion}

To evaluate the oxygen reduction reaction(ORR) activity of catalysts of MOF-900, Cyclic voltammetry (CV) combined with The linear sweep voltammetry(LSV) was performed on RDE in PBS solution because they were desired to be used as electrocatalysts in real MFCs. From Fig. 1(a), clear peaks of the oxygen reduction reaction 
appear in the $\mathrm{O}_{2}$-saturated solution for MOF-900, and almost disappear in the $\mathrm{N}_{2}$-saturated solution, revealing that it was associated with ORR activity.

Fig. 1(b) shows the LSV results of the MOF-800 catalysts. The current density of MOF-800 keeps increasing along with the rotational speed from 250 to $2500 \mathrm{rpm}$ min- 1 . When the current density of the ORR is between $-0.35 \mathrm{~V}$ and $-0.80 \mathrm{~V}$, a stable limit diffusion current region appears. This indicates that the progress of the oxygen reduction reaction is affected by the diffusion rate of the material oxygen to the catalyst surface, and the kinetic process of this system is generally described by the Koutecky Levich equation (K-L).

$$
\begin{gathered}
1 / J=\left(1 / J_{K}\right)+\left(1 / J_{L}\right)=\left(1 / J_{K}\right)+\left(1 /\left(B_{W}^{1 / 2}\right)\right) \\
B=0.62 n F A D_{0}^{2 / 3} v^{-1 / 6} C_{0}
\end{gathered}
$$

The LSV of all samples measured in $\mathrm{O}_{2}$-saturated solution at $1600 \mathrm{rpm}$ min-1 are shown in Fig. 1(c); it is clear that MOF-900 exhibits a more positive onset potential, half-wave potential, and bigger current density (at $-0.6 \mathrm{~V}$ ) than the rest. The details were calculated and are listed in Table 1, indicating that the difference in ORR catalytic activity between MOFs is strongly dependent on the degree of graphitization and the content of different nitrogen species. Different heat treatment temperatures may also produce this change. In particular, a suitable high pyrolysis temperature facilitates the formation of high levels of graphite. Then the high graphitization can further enhance the electrical conductivity of the carbon shell and reduce the thermodynamic barrier of the ORR. Therefore, the significant ORR performance of MOF-900 is attributed to high graphitization, nitrogen doping, great pore structure, and synergistic interactions between carbon atoms and metal centers.

The oxygen reduction reaction is usually carried out by a $2 \mathrm{e}-\left(\mathrm{H}_{2} \mathrm{O}_{2}\right)$ or $4 \mathrm{e}-\left(\mathrm{H}_{2} \mathrm{O}\right)$ mechanism. To further research the pathway of the ORR of the $\operatorname{MOF}(\mathrm{s})$ catalysts, the corresponding limiting current density and the rotational speed at different voltages in the LSV cur ve were selected to Construct K-L curve equation. From Fig. 1(d), the kinetic process of the oxygen reduction reaction with the $\mathrm{MOF}(\mathrm{s})$ catalysts can be fitted well by the K-L equation, illustrating the occurrence of ORR is

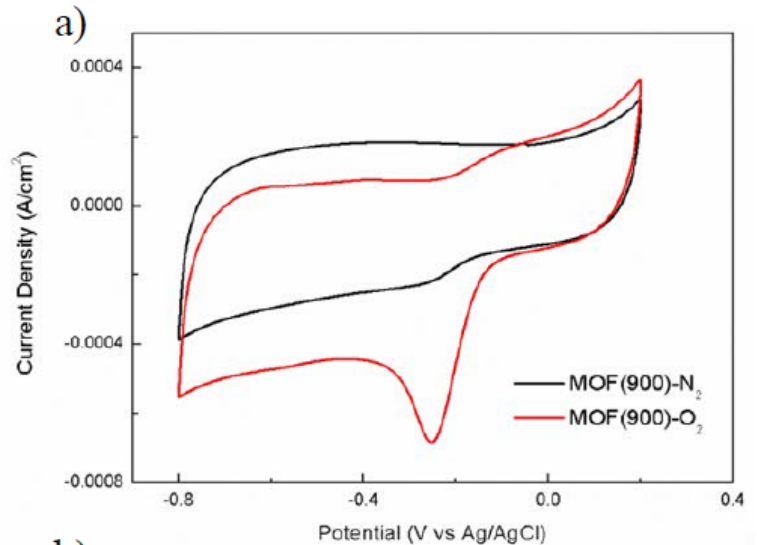

b)
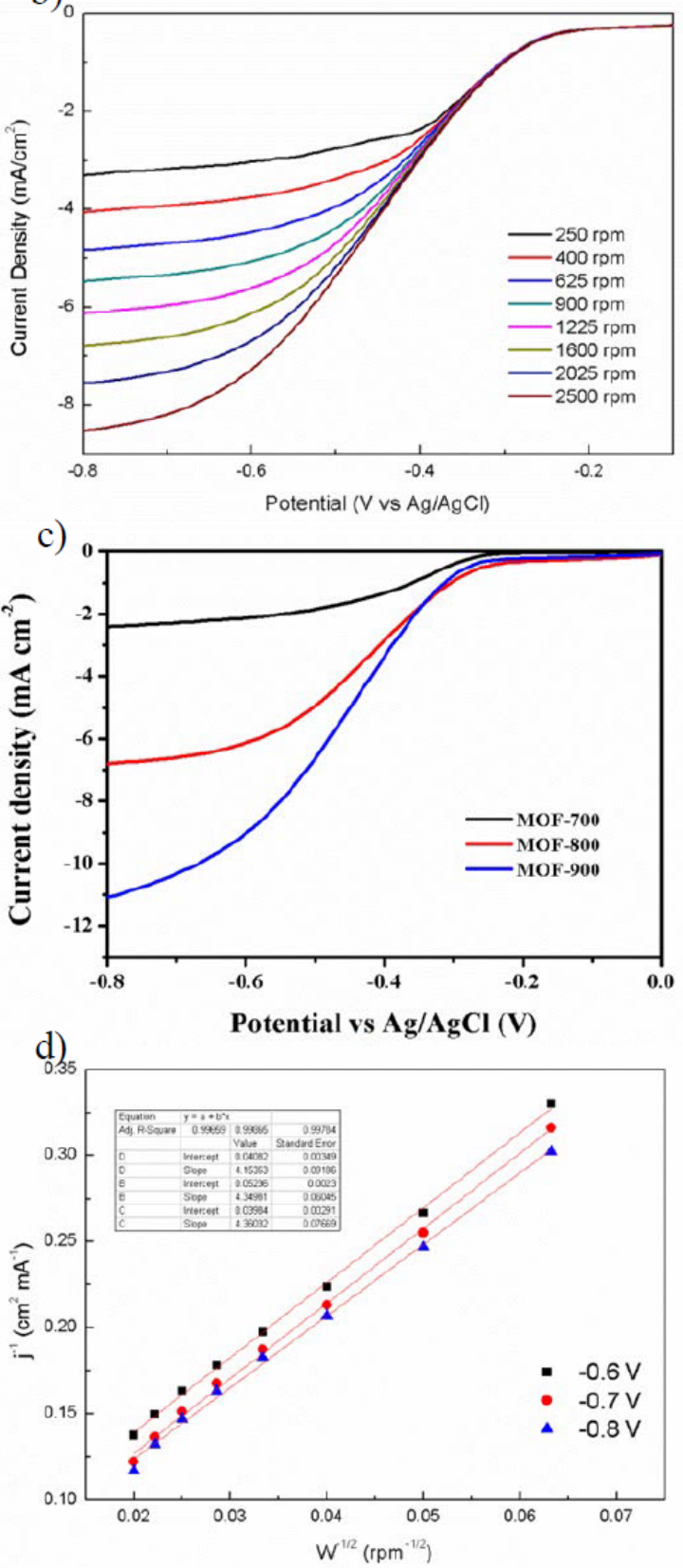

Fig. 1. (a) CV plots of MOF-900 in $\mathrm{O}_{2}$-saturated (red line) and $\mathrm{N}_{2}$-saturated (black line) PBS electrolyte. (b) LSV plots of MOF-800 under different rotation speeds (250-2500 rpm min-1). (c) LSV plots of various catalysts in $\mathrm{O}_{2}$-saturated electrolyte at $1600 \mathrm{rpm}$. (d) Koutecky-Levich plots of MOF900 at different potentials. 
Table 1. Electrochemical results of different catalysts for ORR

\begin{tabular}{|c|c|c|c|}
\hline & MOF-700 & MOF-800 & MOF-900 \\
\hline $\begin{array}{c}\text { On-set } \\
\text { potential (V) }\end{array}$ & 0.02 & 0.03 & 0.04 \\
\hline $\begin{array}{c}\text { Half-wave } \\
\text { potential (V) }\end{array}$ & -0.39 & -0.43 & -0.475 \\
\hline $\begin{array}{c}\text { Current density } \\
\left(\mathrm{mA} \mathrm{cm}^{-2}\right)\end{array}$ & -2.125 & -6.130 & -9.027 \\
\hline
\end{tabular}

based on the first-order reaction kinetics of dissolved oxygen. Moreover, the K-L curves give the electron transfer number (3.5) for MOF-900, indicating that it favors a 4e- ORR process, which is same with $\mathrm{Pt} / \mathrm{C}$ (3.99). Thus, the oxygen reduction react ion with the MOF-900 catalyst is a very efficient catalytic process. To sum up, the catalysts of MOF-900 may have potential to be an effective, high-conductivity, low-cost, and environmentally friendly cathode catalyst for MFCs.

\section{Conclusions}

In summary, the results suggest that $\mathrm{Co} / \mathrm{UiO}-66$ (MOF900) exhibits remarkable ORR electrocatalytic activity, it should be a high-performance electrocatalyst for ORR. $\mathrm{Co} / \mathrm{UiO}-66$ could be a promising oxygen reduction catalyst for application in MFCs.

\section{References}

1. L B E, Nat. Rev. Microbiol, 7(5), 375-81(2009).

2. R. Korneel, R. Rene A, Nat. Rev. Microbiol, 8(10), 706-716(2010).

3. P Prashant, S Vikas N, D Rajendra L, K Sharad P, P Sunil A, P Deepak, Appl. Energy, 168, 706-723(2016).

4. Li M, Zhang H, Xiao T, Wang S, Zhang B, Chen D, Su M, Tang J, Electrochim Acta, 283, 780-788(2018).

5. Kodali M, Herrera S, Kabir S, Serov A, Santoro C, Ieropoulos I, Atanassov P, Electrochim Acta, 265, 5664(2018).

6. Y Liu, K Li, Y Liu, L Pu, Z Chen, S Deng, J. Mater. Chem. A, 3(42), 21149-21158(2015).

7. W Yang, J Li, D Ye, X Zhu, Q Liao, Electrochim. Acta, 224, 585-592(2017).

8. Y Zhang, Y Hu, S Li, J Sun, B Hou, J. Power Sources, 196(22), 9284-9289(2011).

9. S Li, Y Hu, Q Xu, J Sun, B Hou, Y Zhang, J. Power Sources, 213, 265-269(2012).

10. Han T H, Parveen N, Ansari S A, Shim J H, Nguyen A T N, Cho M H, Rsc Advances, 6(105), 103446103454(2016)

11. J Hu, Z Shi, C Su, B Lu, Z Shao, H Huang, Electrochim. Acta, 274, 40-48(2018).

12. Y Xue, S Sun, Q Wang, H Miao, S Li, Z Liu, Electrochim. Acta, 230, 418-427(2017).

13. Han X, Zhang T, Du J, Cheng F, Chen J, Chem Sci, 4,
368-376(2013).

14. Gorlin Y, Lassalle-Kaiser B, Benck JD, Gul S, Webb SM, Yachandra VK, Yano J, Jaramillo TF, J Am Chem Soc, 135, 8525-8534(2013).

15. Liang Y, Wang H, Peng D, Chang W, Hong G, Li Y, Gong M, Xie L, Zhou J, Jian W, J Am Chem Soc, 134, 15849-15857(2012).

16. Huang Y, Wu D, Cao D, Cheng D, Int J Hydrogen Energy, 43, 8611-8622(2018).

17. Pan F, Cao Z, Zhao Q, Liang H, Zhang J, J Power Sources, 272, 8-15(2014).

18. Chen P, Wang L-K, Wang G, Gao M-R, Ge J, Yuan W-J, Shen Y-H, Xie A-J, Yu SK, Energy Environ Sci, 7, 4095-4103(2014).

19. Fu Z, Yan L, Li K, Ge B, Pu L, Zhang X, Biosens Biolelectron, 74, 989-995(2015).

20. Kodali M, Santoro C, Serov A, Kabir S, Artyushkova K, Matanovic I, Atanassov P, Electrochim Acta, 231, 115-124(2017).

21. Santoro C, Serov A, Gokhale R, Rojas-Carbonell S, Stariha L, Gordon J, Artyushkova K, Atanassov P, Appl Catal, B, 205, 24-33(2017).

22. Guo C, Tong $\mathrm{X}$, Guo XY, Int J Hydrogen Energy, 41(2016).

23. Ma X, Zhao X, Huang J, Sun L, Li Q, Yang X, ACS Appl Mater Interfaces, 9, 21747-21755(2017).

24. Peng H, Liu F, Liu X, Liao S, You C, Tian X, Nan H, Luo F, Song H, Fu Z, ACS Catal, 4, 3797-3805(2014).

25. Ben Liew K, W R W Daud, Ghasemi M, Leong J X, Lim W S, Ismail M, Int. J. Hydrog. Energy, 39(10), 4870-4883(2014).

26. Morozan A, Jaouen F, Energy Enviro. Sci. 5(11), 9269-9290(2012).

27. Afsahi F, Kaliaguine S, J. Mater. Chem. A, 2(31), 12270-12279(2014).

28. Fu SF, Zhu CZ, Zhou YZ, Yang GH, Jeon JW, Lemmon J, Du D, Nune SK, Lin YH, Electrochim. Acta, 178, 287-293(2015).

29. Yu H Y, Fisher A, Cheng D J, Cao D P, ACS Appl. Mater. Interfaces, 8(33), 21431-21439(2016).

30. L Chen, Y Li, N Xu, G Zhang, Carbon, 132, 172180(2018).

31. Tang H, Cai S, Xie S, Wang Z, Tong Y, Pan M, Lu X, Adv Sci. 3, 1500265(2016).

32. You S J, Gong X B, Wang W, Qi D P, Wang X H, Chen $X$ D, Ren N Q, Adv. Energy Mater. 6(1), 1501497(2016).

33. Fu Y, Huang Y, Xiang Z, Liu G, Cao D, Eur J Inorg Chem, 2016, 2100-2105(2016). 